\title{
THE USE OF DEXMEDETOMIDINE FOR THE TREATMENT OF ARRHYTHMIAS AFTER PEDIATRIC CARDIAC SURGERY
}

\author{
Kovacikova L, Krasnanova V, Skrak P, Hrubsova Z, Zahorec M
}

CICU, Pediatric Cardiac Center, National Institute of Cardiovascular Diseases, Bratislava Slovakia

-Arrhythmias after cardiac surgery can be a therapeutic challenge, since antiarrhythmics may be ineffective and associated with adverse effects.

-Dexmedetomidine is a highly selective $\alpha 2$-adrenergic agonist used for sedation and monitored anesthesia. Dexmedetomidine can have an adverse impact on the cardiovascular system secondary to its negative chronotropic and dromotropic effects. However, the cardiac effects may represent a therapeutic option for the treatment of perioperative tachyarrhythmias.

- This study evaluates dexmedetomidine as a first line therapy for management of postoperative arrhythmias in children with congenital or acquired cardiac diseases.

Methods

Retrospective study within the period of May 2014 - December 2017 evaluated 65 patients who received dexmedetomidine as a primary drug for postoperative arrhythmias.

The restoration of sinus rhythm or slowing of tachycardia to rate that allowed atrial or atrioventricular sequential pacing was considered as efficacy of therapy

Continuous data are presented as median (range)

Patients

Sixty-five patients with median age of 2.0 months $(1$ day -16 years $)$ received dexmedetomidine for several types of arrhythmias (Table 1). Main cardiac diagnoses of the patients are shown in Table 2.

Table 1. Types of arrhythmias treated with dexmedetomidine

\begin{tabular}{lc} 
Types of arrhythmias & No. of Patients \\
\hline Junctional ectopic tachycardia (JET) & 45 \\
Supraventricular premature beats & 8 \\
Supraventricular tachycardia other than JET & 6 \\
Atrial flutter & 1 \\
Ventricular tachycardia & 1 \\
Ventricular premature beats & 4 \\
\hline
\end{tabular}

Table 2. Cardiac diagnoses of the patients

\begin{tabular}{lc}
\hline Primary cardiac diagnosis & No. of Patients \\
\hline Ventricular septal defect \pm atrial septal defect & 11 \\
Tetralogy of Fallot & 11 \\
Atrio-ventricular septal defect & 10 \\
D-Transposition of great arteries & 7 \\
Others & 26 \\
\hline
\end{tabular}

Results

Administration of dexmedetomidine

Fifteen (23\%) patients received initial loading dose of $1 \mathrm{mcg} / \mathrm{kg}$ $(0.8-1.2 \mathrm{mcg} / \mathrm{kg})$.

A continuous infusion with a maximum dose of $1 \mathrm{mcg} / \mathrm{kg} / \mathrm{h}(0.3-2 \mathrm{mcg} / \mathrm{kg} / \mathrm{h})$ was administered in all patients.

In 4 patients transient blood pressure decrease occurred in association with dexmedetomidine. Hypotension responded to volume and/or calcium administration.
Effectiveness of dexmedetomidine as a first line therapy

Dexmedetomidine administration was associated with arrhythmia cessation in $37(57 \%)$ patients.

Risk factors for dexmedetomidine failure as a single antiarrhythmic agent

\begin{tabular}{lcc}
\hline Risk factor & P & AUC \\
\hline Lower patient weight & 0.02 & 0.62 \\
Lower patient age & 0.031 & 0.62 \\
Higher maximum heart rate & 0.004 & 0.69 \\
\hline
\end{tabular}

The escalation of antiarrhythmic therapy

The escalation of treatment was required in $28(43 \%)$ patients.

The second line therapy is shown in Table 3.

Table 3. Second line therapy

\begin{tabular}{lc}
\hline Treatment modality & No. of Patients \\
\hline Amiodarone & 25 \\
Sotalol & 1 \\
Adenosine & 1 \\
Amiodarone with subsequent ECMO & 1 \\
\hline
\end{tabular}

$\mathrm{ECMO}=$ extracorporeal membrane oxygenation

Amiodarone as a second line treatment

Amiodarone was administered in $\mathbf{2 5}$ patients as:

- boluses of $4.5 \mathrm{mg}(1-10 \mathrm{mg})$

- continuous infusion with maximum dose of $15 \mathrm{mcg} / \mathrm{kg} / \mathrm{min}(10-20 \mathrm{mcg} / \mathrm{kg} / \mathrm{min})$.

- In 1 patient, bradycardia and hypotension occurred following administration of amiodarone boluses ( $5 \mathrm{mg} / \mathrm{kg}$ ).

- Amiodarone infusion was used concomitantly with dexmedetomidine infusion in 10 patients during 29.5 hours ( 9 - 98 hours) without side effects.

Patient outcome

- In 64 patients, arrhythmia did not recure in late postoperative period.

- One patient with ventricular arrhythmia and cardiomyopathy died due to septic shock.

- Long-term therapy with amiodaron and sotalol was required in the patient with IART and AVRT, respectively. (IART = intraatrial reentrant tachycardia , AVRT = atrioventricular atrioventricular reentrant tachycardia

\section{Conclusion}

The study suggests that dexmedetomidine as a first line antiarrhythmic drug has a therapeutic role in the treatment of postoperative arrhythmias after pediatric cardiac surgery.

REFERENCES

Chrysostomou C, Beerman L, Shiderly D, Berry D, Morell VO, Munoz R. Dexmedetomidine: a novel drug for the treatment of atrial and junctional tachyarrhythmias during the perioperative period for congenital cardiac surgery: a preliminary study. Anesth Analg. 2008:107:1514-22.

Turan A, Bashour_CA, You_J, Kirkova Y, Kurz A, Sessler_DI, Saager L. Dex

Shuplock JM Smith AH, Owen J, Van Driest SL Mad PJ. Association between perioperative dexmedetomidine and arrhythmias after surgery for congenital heart disease. Circ Arrhythm Electrophysiol 2015;8:643-50 